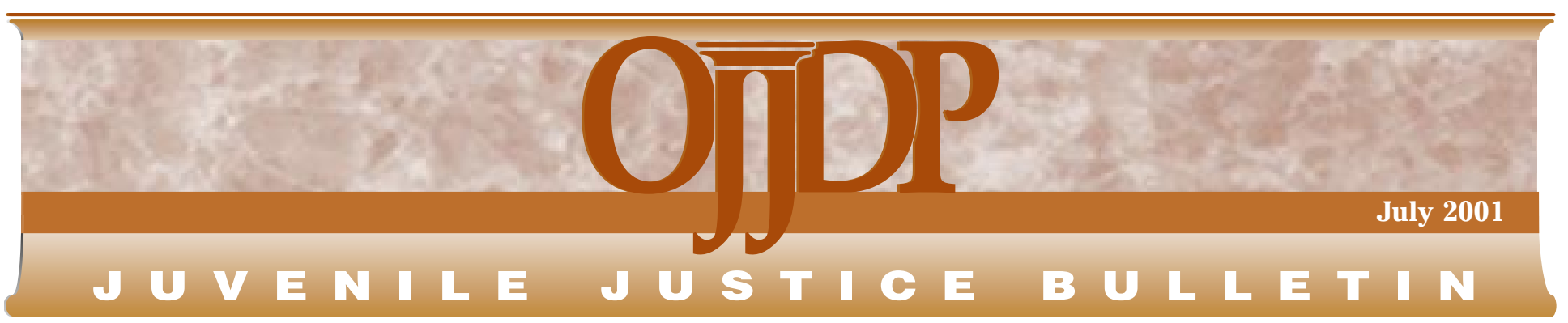

\title{
Preventing Delinquency Through Improved Child Protection Services
}

\section{Richard Wiebush, Raelene Freitag, and Christopher Baird}

After increasing sharply in the early 1990s, rates of juvenile violent crime have been declining since 1993 (Snyder and Sickmund, 1999). Enhanced prevention and intervention efforts have had an impact. Yet, this encouraging trend should not invite tolerance of the status quo or inhibit efforts to drive rates still lower. This Bulletin examines a potentially powerful, yet often overlooked, delinquency prevention strategy: efforts to reduce the incidence of childhood maltreatment. The link between experiencing maltreatment as a child and committing offenses as a juvenile is profound. A substantial body of research (discussed more fully later) has shown that:

- Maltreated children are significantly more likely than nonmaltreated children to become involved in delinquent and criminal behavior.

- The prevalence of childhood abuse or neglect among delinquent and criminal populations is substantially greater than that in the general population.

- Delinquent youth with a history of abuse or neglect are at higher risk of continuing their delinquent behavior than delinquents without such a history.

It follows, then, that if it were possible to reduce the incidence of children's maltreatment, delinquency rates would decline. Reducing the maltreatment of children is a goal best addressed on multiple levels - that is, through primary, secondary, and tertiary prevention efforts. ${ }^{1}$ Reducing childhood maltreatment also requires fundamental social changes in areas that contribute to increased rates of maltreatment (e.g., poverty). This Bulletin focuses on a tertiary prevention strategy that shows great promise in reducing subsequent maltreatment once a family has come to the attention of a child protection services (CPS) agency.

The Bulletin begins with a brief review of what is known about the link between childhood maltreatment and juvenile and adult offending. Next, it provides an overview of OJJDP's Comprehensive Strategy for Serious, Violent, and Chronic Juvenile Offenders and identifies where CPS tertiary prevention efforts belong within a community's continuum of delinquency prevention and intervention efforts. The main body of the Bulletin describes and assesses a particularly

\footnotetext{
1 In this Bulletin, "primary prevention" refers to activities that are directed at whole population groups, "secondary prevention" refers to activities directed at persons who have not yet experienced an incident of maltreatment but are deemed at increased risk of doing so, and "tertiary prevention" refers to activities directed at those who have experienced a first target event and efforts to prevent subsequent events.
}

\section{A Message From OJJDP}

As discussed in this Bulletin, research indicates that the prevalence of child abuse or neglect among delinquent offenders is substantially greater than it is among the general population. Moreover, maltreated children are significantly more likely to become involved in delinquent behavior than their nonmaltreated peers, and delinquent youth with a history of abuse or neglect are more likely to continue their offending behavior than delinquents who have not suffered child abuse or neglect.

Given the links between child maltreatment and juvenile offending, designing and implementing programs to reduce the incidence of child maltreatment as a means of preventing delinquency are a promising - though often overlooked-strategy.

After reviewing what is known about the links between childhood maltreatment and juvenile and adult offending, the authors review OJJDP's Comprehensive Strategy for Serious, Violent, and Chronic Juvenile Offenders and examine the role that child protective services' prevention efforts can play in delinquency prevention and intervention.

Programs that prevent child abuse and neglect or that intervene effectively when child maltreatment occurs can also serve as effective strategies to prevent future delinquency. It is our hope that the information in this Bulletin will serve both of those worthy program goals. 
promising CPS tertiary prevention strategy known as Structured Decision Making (SDM).

\section{Research on the Effects of Childhood Maltreatment}

\section{Childhood Maltreatment and Subsequent Offending}

Researchers use two basic approaches to examine the possible link between childhood maltreatment and subsequent offending. The first approach is to sample maltreated children and follow them (retrospectively or prospectively) to observe rates of subsequent offending. The second approach is to sample juvenile or adult offenders and measure the rate at which they experienced maltreatment in childhood. Both approaches are strengthened when data on the maltreated sample group are compared with those for a nonmaltreated control group. Both approaches may use a variety of methods to define childhood maltreatment including self-reporting, referral to a CPS agency, substantiation of a CPS report, or court involvement related to childhood maltreatment victimization. Similarly, subsequent offending may be defined by selfreport, arrest, or conviction. Some studies also examine the relationship between maltreatment and subsequent at-risk behaviors such as committing status offenses, becoming pregnant as a teenager, having a low grade point average (GPA), or experiencing mental health problems. The growing body of research on these issues uses a variety of methodologies but leads to a similar conclusion: "In general, people who experience any type of maltreatment in childhood ... . are more likely than people who were not maltreated to be arrested later in life" (Widom, 1995:4).

A closer examination of this body of research provides further details on the connections between abuse and delinquency. Several studies have examined the prevalence of abuse and neglect among delinquent and criminal populations and found that these populations have strikingly higher rates of childhood abuse and neglect than the general population. National estimates in 1997 indicated that approximately 4 percent of all children were reported to child welfare agencies as alleged victims of abuse or neglect (U.S. Department of Health and Human Services, Administration on Children, Youth and Families, 1999). In contrast:

- A study of court-referred juvenile offenders in Milwaukee County, WI, found that 66 percent of male offenders and 39 percent of female offenders previously had been victims in substantiated reports of abuse or neglect (Pawaserat, 1991).

- A study of high-risk male juvenile parolees in three States revealed that the proportion of juveniles who had allegedly been victims of abuse or neglect ranged from 29 percent in Virginia to 45 percent in Colorado to 53 percent in Nevada (Wiebush, McNulty, and Le, 2000).

Findings are similar for adult offenders. For example, an estimated 5-8 percent of the general adult male population and 12-17 percent of the adult female population in the United States were physically or sexually abused as children (Gorey and Leslie, 1997). However, a recent study of adult offenders found that 16 percent of males and 57 percent of females in State prisons had experienced childhood physical or sexual abuse (Harlow, 1999).

Several empirically based risk assessment studies conducted by the National Council on Crime and Delinquency (NCCD) provide additional data linking childhood maltreatment and subsequent delinquency. These studies identify jurisdiction-specific risk factors that States use to assess and classify juvenile probationers and parolees according to their likelihood of committing subsequent offenses. In at least five States-Michigan, Nebraska, Rhode Island, Virginia, and Wisconsin (National Council on Crime and Delinquency, 1995a, 1995b, 1995c, 1997, 1999)—a prior allegation or confirmation of childhood abuse or neglect has been identified as an important risk factor for continuing delinquency. In Rhode Island, for example, juvenile probationers who were childhood victims of abuse or neglect recidivated at more than 1.5 times the rate of youth who had not been victimized (71 percent versus 46 percent).

Two conceptually and methodologically important research efforts have compared maltreated children with nonmaltreated children to determine the impact of maltreatment on subsequent offending in general and violent offending in particular. First, in a study that was part of the OJJDP-funded longitudinal Rochester Youth Development Study, researchers examined the official and self-reported delinquency of a general population sample of 1,000 juveniles, 16 percent of whom had substantiated reports of abuse or neglect as children (Kelley, Thornberry, and Smith, 1997). The study compared the maltreated and nonmaltreated groups on the extent and frequency of their delinquent involvement. Among the study's key findings are the following:

- Youth who had been victims of child abuse or neglect were significantly more likely than nonvictims to have an official record of delinquency (45 percent versus 32 percent).

- Compared with youth who had not experienced childhood maltreatment, maltreated youth self-reported significantly greater involvement in delinquent behavior (79 percent versus 70 percent), serious delinquent behavior (42 percent versus 33 percent), and violent delinquent behavior (70 percent versus 56 percent).

- The frequency of official and selfreported delinquent acts was significantly higher for maltreated youth than for youth who had not been maltreated.

- As the frequency and severity of maltreatment increased, there were significant increases in the frequency of subsequent offending. In fact, the number of arrests among juveniles who had experienced multiple incidents of maltreatment (or multiple types of maltreatment or particularly severe maltreatment) as children was twice as high as the number among juveniles who had experienced less frequent or less severe maltreatment.

Second, Widom and her associates conducted a series of well-designed studies that compared the delinquent and criminal outcomes of a sample of maltreated children with those of a matched sample of nonmaltreated children (Widom, 1992; Widom, 1995; Maxfield and Widom, 1995). All the children $(n=1,575)$ were followed through their teenage years into adulthood to determine the extent of their delinquent and criminal activity. Key findings include the following: 
- Juvenile arrest rates for the two groups differed significantly: 27 percent of the maltreated children (versus 17 percent of the nonmaltreated children) were arrested as juveniles. Moreover, the maltreated children had a higher average number of juvenile arrests than the nonmaltreated children (3.0 versus 2.4).

- Adult arrest rates for the two groups were also significantly different: 42 percent of the maltreated children were arrested as adults, compared with 33 percent of the nonmaltreated children. In addition, the maltreated children had a higher average number of adult arrests (5.7 versus 4.2).

- Both the maltreated and nonmaltreated groups included a substantial number of individuals who did not offend as juveniles but who were arrested as adults. The maltreated children, however, were significantly more likely than the nonmaltreated children to evidence this "adult onset" of criminal behavior (31 percent versus 26 percent).

- The maltreated children were also significantly more likely than the nonmaltreated children to commit violent offenses as teenagers and young adults.

\section{Childhood Maltreatment and Other At-Risk Behaviors}

Childhood maltreatment has been linked to a number of other adolescent problems. Compared with nonmaltreated matched control groups, abused or neglected children are significantly more likely to engage in violent behavior, become pregnant during adolescence, use drugs, have lower GPAs, and/or experience mental health problems (Kelley, Thornberry, and Smith, 1997). (See figure 1.)

Several other studies have reached similar conclusions, indicating that maltreated children are at increased risk of both delinquency (Bolton, Reich, and Gutierres, 1977; Alfaro, 1981; English, 1997) and other problems during adolescence (Dembo et al., 1992; Silverman, Reinherz, and Giaconia, 1996). As Kelley and colleagues have noted (1997:11):

Maltreatment diminishes the likelihood that children will come

\section{Figure 1: Relationship Between Child Maltreatment and Various Outcomes During Adolescence}

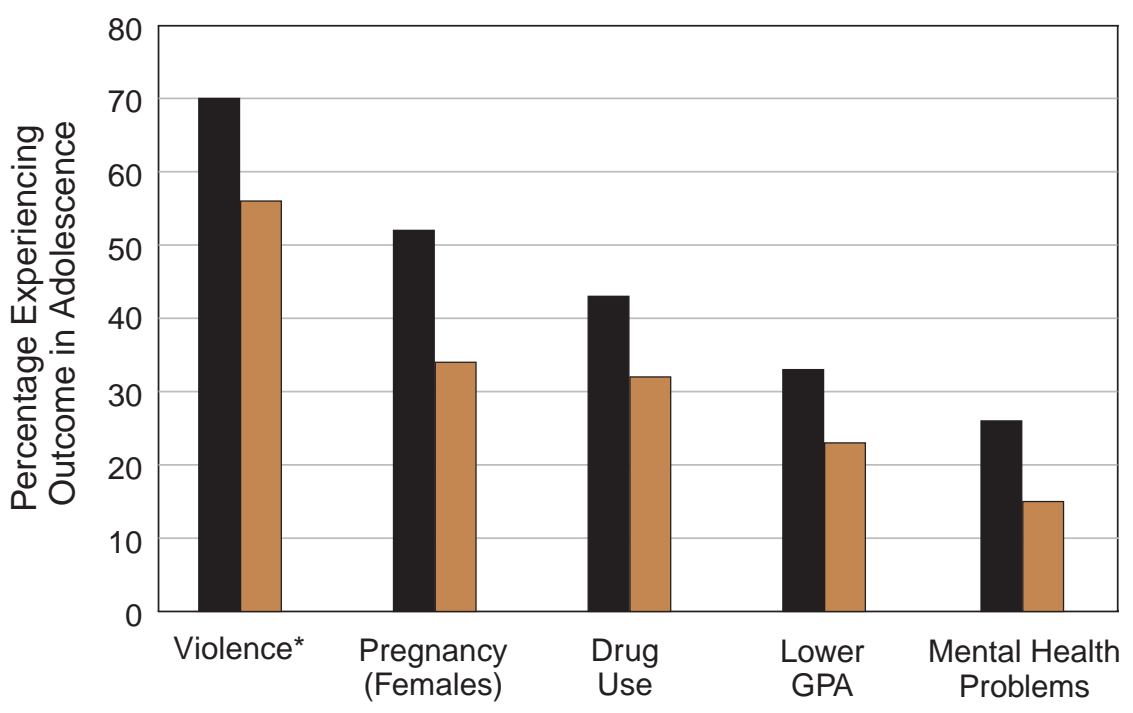

Outcome

Maltreated in childhood
Nonmaltreated in childhood (matched control groups)

* Violence is a measure of self-reported involvement in one or more of the following: assault, assault with a weapon, involvement in gang fights, and forcible robbery.

Source: Kelley, Thornberry, and Smith, 1997.

through adolescence with no serious problems. Moreover, a history of childhood maltreatment nearly doubles the risk that teenagers will experience multiple problems during adolescence.

Still, most maltreated children do not become delinquents. What is it that keeps some maltreated children from being arrested as juveniles? Kelley and colleagues suggest that there may be "intervening factors, including the emergence of protective factors and the provision of effective services" (Kelley, Thornberry, and Smith, 1997:13). This Bulletin examines how CPS agencies can provide more "effective services" and potentially ward off subsequent delinquent/criminal involvement by abused and neglected children.

\section{OJJDP's Comprehensive Strategy and the Role of CPS}

In its 1995 Guide for Implementing the Comprehensive Strategy for Serious, Violent, and Chronic Juvenile Offenders, OJJDP emphasizes the need for delinquency prevention, stressing that it is the "most costeffective approach to reducing juvenile delinquency" (Howell, 1995:7). In fact, prevention efforts constitute one of the two primary components of the Comprehensive Strategy (the other being reform of the juvenile justice system). The Comprehensive Strategy uses a risk-focused approach to prevention efforts-meaning that it requires careful attention to factors identified through research as precursors to delinquency, violence, and other problem behaviors. As shown in figure 2 (page 4), the Comprehensive Strategy divides such risk factors into four basic domains: community, family, school, and individual/ peer. Central to the focus of this Bulletin are family risk factors. In defining family risk factors, the Comprehensive Strategy specifies that "family management problems" include failure to supervise and monitor children and excessively severe, harsh, or inconsistent punishment; "family conflict" includes domestic violence; and "family history of the problem behavior" includes caregiver substance abuse (Howell, 1995:20). Significantly, these family risk factors for delinquency and violence are also characteristics typically present in abusive or neglectful families. These 
Figure 2: Risk Factors for Health and Behavior Problems

\begin{tabular}{|c|c|c|c|c|c|}
\hline \multicolumn{6}{|l|}{ Risk Factor } \\
\hline \multicolumn{6}{|l|}{ Community } \\
\hline Availability of drugs & $\checkmark$ & & & & $\checkmark$ \\
\hline Availability of firearms & & $\checkmark$ & & & $\checkmark$ \\
\hline $\begin{array}{l}\text { Community laws and norms favorable } \\
\text { toward drug use, firearms, and crime }\end{array}$ & $\checkmark$ & $\checkmark$ & & & $\checkmark$ \\
\hline Media portrayals of violence & & & & & $\checkmark$ \\
\hline Transitions and mobility & $\checkmark$ & $\checkmark$ & & $\checkmark$ & \\
\hline $\begin{array}{l}\text { Low neighborhood attachment and community } \\
\text { organization }\end{array}$ & $\checkmark$ & $\checkmark$ & & & $\checkmark$ \\
\hline Extreme economic deprivation & $\checkmark$ & $\checkmark$ & $\checkmark$ & $\checkmark$ & $\checkmark$ \\
\hline \multicolumn{6}{|l|}{ Family } \\
\hline Family history of problem behavior & $\checkmark$ & $\checkmark$ & $\checkmark$ & $\checkmark$ & $\checkmark$ \\
\hline Family management problems & $\checkmark$ & $\checkmark$ & $\checkmark$ & $\checkmark$ & $\checkmark$ \\
\hline Family conflict & $\checkmark$ & $\checkmark$ & $\checkmark$ & $\checkmark$ & $\checkmark$ \\
\hline $\begin{array}{l}\text { Favorable parental attitudes toward and } \\
\text { involvement in the problem behavior }\end{array}$ & $\checkmark$ & $\checkmark$ & & & $\checkmark$ \\
\hline \multicolumn{6}{|l|}{ School } \\
\hline Early and persistent antisocial behavior & $\checkmark$ & $\checkmark$ & $\checkmark$ & $\checkmark$ & $\checkmark$ \\
\hline Academic failure beginning in elementary school & $\checkmark$ & $\checkmark$ & $\checkmark$ & $\checkmark$ & $\checkmark$ \\
\hline Lack of commitment to school & $\checkmark$ & $\checkmark$ & $\checkmark$ & $\checkmark$ & $\checkmark$ \\
\hline \multicolumn{6}{|l|}{ Individual/Peer } \\
\hline Rebelliousness & $\checkmark$ & $\checkmark$ & & $\checkmark$ & \\
\hline Friends who engage in the problem behavior & $\checkmark$ & $\checkmark$ & $\checkmark$ & $\checkmark$ & $\checkmark$ \\
\hline Favorable attitudes toward the problem behavior & $\checkmark$ & $\checkmark$ & $\checkmark$ & $\checkmark$ & \\
\hline Early initiation of the problem behavior & $\checkmark$ & $\checkmark$ & $\checkmark$ & $\checkmark$ & $\checkmark$ \\
\hline Constitutional factors & $\checkmark$ & $\checkmark$ & & & $\checkmark$ \\
\hline
\end{tabular}

Source: Catalano and Hawkins, 1995; updated 1998-2000 by Developmental Research and Programs, Inc. identified risk factors, considered in conjunction with the clear link between childhood maltreatment and subsequent delinquency, strongly suggest that child welfare agencies and their efforts to reduce child abuse and neglect have a central role for delinquency prevention within the context of the Comprehensive Strategy.

\section{Structured Decision Making: Background}

The primary goals of the Structured Decision Making model are to (1) bring a greater degree of consistency, objectivity, and validity to child welfare case decisions and (2) help CPS agencies focus their limited resources on cases at the highest levels of risk and need. Structured assessment tools are used at various points in the case decision-making process (e.g., initial response to allegations, child removal, case opening/closing, and reunification). Each tool incorporates decision protocols-based directly on assessment results-to guide the agency's response to each family. One of the key assessment tools is a research-based risk assessment that classifies families according to their likelihood of continuing to abuse or neglect their children.

SDM, then, focuses on how case management decisions are made and how agency resources can best be directed. Ultimately, SDM is a strategy designed to reduce subsequent maltreatment rates by improving both the efficiency and effectiveness of CPS agencies. To the extent that SDM accomplishes these goals-and available research indicates that it does-the system will have the added benefit of reducing the rate at which maltreated children subsequently become involved in the juvenile and/or criminal justice system.

\section{Origins of SDM}

In addition to its use in addressing the link between childhood maltreatment and subsequent delinquency, SDM has another tie to the juvenile justice system. A core component of SDM is the use of researchbased risk assessment tools. The risk assessment methodology was originally developed to classify juvenile offenders according to their likelihood of committing additional offenses. In 1986 (in Alaska) and 1988 (in Michigan), the Children's Research Center (CRC), a division of NCCD, worked with State agencies to 
develop a research-based risk assessment tool for use with their delinquent populations. In both States, the agency that was responsible for juvenile justice also administered CPS. Knowing the value of risk assessment to decision making and resource utilization in the juvenile justice system, the Alaska and Michigan administrators raised the question of whether a similar tool could be used to identify which CPS families with at least one known incident of maltreatment were at highest risk of future maltreatment. Such a tool, the States reasoned, could help them make better decisions about which families to serve. In response, CRC staff conducted research in both States and found that fairly simple and highly effective tools could be constructed to identify families with low, moderate, and high risk of reabuse (Baird, Wagner, and Neuenfeldt, 1992).

Shortly before the CRC studies in Alaska and Michigan, Will Johnson conducted similar research in Alameda County, CA, and reached the same conclusion (Johnson and L'Esperance, 1984). It is not surprising that two independent studies confirmed the effectiveness of research-based risk assessment for CPS agencies. Although a substantial body of literature has demonstrated the effectiveness of empirical risk assessment in other human service fields, many in the child welfare field felt that the risk of childhood maltreatment was too complex an issue to be distilled to a short list of variables. However, it is precisely because human behavior is so complex that assessments based on a simple tool are generally more accurate than those based on clinical judgment (Dawes, Faust, and Meehl, 1989).

Since 1988, when CRC implemented the first research-based risk assessment scale for child welfare in Alaska's CPS system, it has conducted 11 risk studies in jurisdictions ranging from Rhode Island to California to South Australia. As the use of research-based risk assessment spread, it became evident that although risk assessment provided critical information for some CPS decisions, other key decision points required different types of structured assessments. Hence, the SDM model has been expanded to address most vital decisions, from the initial decision of whether to initiate an investigation to the final decision of when to close a case. Not all of these decisions lend themselves to the use of research-based assessment methodologies; some require consensus-based approaches. However, all decision points in the child welfare case management process can use structured assessment tools that clearly identify what factors need to be considered by all staff and how those factors relate to the decision.

\section{The Need for SDM in Child Welfare Services}

The number of abuse and neglect allegations nationwide has risen dramatically during the past two decades. Most child welfare agencies have been hard pressed to respond effectively, as new demands have outpaced available resources. As a result, the Nation has seen class action lawsuits challenging the quality of services provided in more than 30 States, media exposés resulting from child deaths, increased concerns over worker and agency liability, and a continuous search for new strategies and resources to address the burgeoning problem.

Child welfare agencies' need for additional resources is obvious but not the only issue. Increasing pressures have highlighted a problem that has long plagued human services agencies in general and child welfare agencies in particular: the need for more efficient, consistent, and valid decision making. Child protection workers must make extremely difficult decisions. Yet, in many agencies, workers have widely different levels of training and experience. Consequently, decisions regarding case openings, child removal and reunification, and service provision have long been criticized as inappropriate and/or inconsistent. In fact, research has clearly demonstrated that decisions regarding the safety of children vary significantly from worker to worker, even among those considered to be child welfare experts (Rossi, Schuerman, and Budde, 1996). As the pressure to make critical decisions affecting children and families rises, so does the potential for error. Inappropriate decisions can be costly and may result in the overuse of out-of-home placements or, tragically, the injury or death of a child.

Problems of increasing referrals, limited resources, and liability exposure are inextricably linked with decision-making issues. Agencies overwhelmed by heavy workloads need to be able to consistently and accurately determine which cases should be investigated, which children need to be removed from their homes, and which families require the most intensive services. Clearly, new methods are required to help agencies and workers make decisions as efficiently and effectively as possible. Tools are also needed to help workers make accurate and reliable assessments of both immediate safety issues and long-term risk. Decisionmaking strategies are needed to help agencies focus limited resources on those families at the highest level of risk. These decision-making tools must be embedded in case management systems that incorporate clearly defined service standards, mechanisms for frequent reassessments, methods for measuring workload, and procedures for ensuring accountability and quality control.

How child welfare decisions are made and how agencies use resources are the key questions addressed by CRC's SDM model. The SDM model provides a comprehensive, systematic approach to case management, resource management, performance monitoring, quality assurance, and program and policy evaluation. The four principles that form the foundation of SDM are presented in the next section, followed by an indepth discussion of the major components of the model.

\section{Principles of the SDM Model}

The SDM model is based on four primary principles.

First, because decisions can be significantly improved when they are structured appropriately, every worker in every case must consider specific criteria through highly structured assessment procedures. Failure to clearly define decision-making criteria and identify how workers should apply these criteria results in inconsistency and, sometimes, inappropriate case actions.

Second, priorities assigned to cases and service plans (or responses) must correspond directly to results of the assessment process. The assessment process has little meaning unless its results lead directly to an appropriate decision. Decisions should be structured to ensure that the agency's highest priority is given to the most serious and/or the highest risk cases. Moreover, if agencies are to translate priority setting into practice, 
they must have clearly identified and consistently implemented service standardsdifferentiated by level of risk-for each type of case. Such differential service standards help focus how resources are used and provide a degree of accountability often missing in human services agencies. To ensure that the assessment process results in improved service, expectations for staff regarding the process must be clearly defined and practice standards must be readily measurable.

Third, virtually everything that an agency does-from providing services in an individual case to budgeting for treatment resources-should be a response to the assessment process. Risk and needs assessments, for example, should be linked directly to service plans. In the aggregate, assessment data also will help indicate the range and extent of service resources needed in a community. Similarly, assessment and case classification results are directly related to agency service standards, which in turn drive staff workload and budgeting requirements.

Fourth, a single, rigidly defined model cannot meet the needs of every agency. Not all State and county child welfare agencies are organized to deliver services in the same way. Nor do they always share similar service mandates. As a result, the CRC approach to designing an SDM system is collaborative and engages agencies in a joint development effort. Each system is built on a set of principles and components that are then adapted to local practices and mandates. The development process incorporates a great deal of input from local managers and staff. The result is a site-specific system that is "owned" by the agency and builds on its particular strengths as a service organization.

\section{The SDM Model}

The SDM model consists of a set of assessment instruments augmented by management components that provide accountability, quality assurance, and planning, budgeting, and evaluation data. Each assessment tool is designed specifically for use at a key decision point in the life of a CPS case. By focusing on particular decision points rather than attempting to address multiple issues with a single tool, the SDM model enhances clarity and allows agencies to more effectively monitor compliance with established policies and procedures. Although SDM tools identify the critical assessment factors for each decision point, the model also includes ways to account for unique case characteristics that may not have been captured on the assessment instrument. Most SDM tools incorporate an override provision that allows workers to change the assessment-indicated decision, when necessary. SDM does not replace worker judgment; instead, it provides an objective framework within which to articulate agency policy, thereby helping ensure that "best practices" are applied to all cases.

The primary tools used in SDM sites are discussed below.

\section{Response Priority Assessment}

Most jurisdictions begin the SDM assessment processes after deciding to investigate a referral. At this point, a set of decision trees (see figure 3 ) guides caseworkers through key questions that allow them to determine how quickly to respond to the referral. For example, Cuyahoga County, $\mathrm{OH}$, sorts all investigations into three groups: Priority 1 (those requiring a response within 1 hour), Priority 2 (response within 24 hours), and Priority 3 (response within 72 hours). Different decision trees are used to address different types of maltreatment (e.g., neglect, physical abuse, sexual abuse).

Figure 3 illustrates a response priority system for use in cases of alleged physical abuse. Under this system, the answer to each question directs the worker to the next question to be asked and, rather quickly, to a presumptive response level. Because of differences in State statutes and agency policy, response priority systems vary somewhat among jurisdictions. All systems, however, ensure that workers systematically apply certain key criteria to every case.

$\mathrm{CRC}$ researchers have assessed the effectiveness of response priority tools using SDM management data in California (Children's Research Center, 2000). The research questions were whether and to what extent the child removal (i.e., out-ofhome placement) rate was higher in cases that required an "immediate response" than the rate in cases that had been assigned a lower priority. Since the tools are designed to prioritize referrals based on the seriousness of the allegations, one would expect-if the tools are valid-to see a much higher rate of removal in the "immediate response" cases. The results provided strong support to the design of the response priority tools. They showed that over a 6 -month period, the proportion of removals in the immediate response cases was four times higher than it was in the cases that were given lower priority (13 percent versus 3.2 percent).

\section{Safety Assessment}

When a CPS investigator first makes contact with a family, the worker must determine whether there are any immediate, pressing conditions that threaten the safety of the child. An SDM safety assessment generally consists of three parts. The first is a list of potential threats to children in the family-that is, conditions that would place a child in danger of immediate harm. Figure 4 (page 8) shows an example of the first section of a safety assessment. The second section is an identification of the short-term interventions selected by the worker (e.g., monitoring by a neighbor or relative), which will constitute a safety plan, and the third is simply a record of the final decision.

Safety assessments should be completed during a CPS investigator's first face-toface contact with the family. If safety issues are present, workers are directed to consider a series of potential in-home interventions, beginning with the least restrictive. If in-home interventions are unavailable, refused, or insufficient to mitigate identified safety issues, placement emerges as the only alternative. All protective placements are based on the determination that available in-home interventions would fail to offer adequate protection for the child.

Although safety assessments may be characterized as simple checklists, their value cannot be overstated. Simplicity is, in fact, key to successful implementation, because CPS investigators are required to make decisions within very limited timeframes. By allowing investigators to focus on a relatively small set of important factors, safety assessments help investigators avoid mistakes and improve consistency.

Like the response priority decision trees discussed earlier in this Bulletin, safety assessments help ensure that CPS staff assess all cases based on a standardized set of issues. Safety assessments also require that agencies have a safety plan whenever any safety factor (i.e., a condition that threatens immediate harm) has been identified, thereby adding accountability to the process. 
Figure 3: Response Priority Decision Tree: Physical Abuse Cases (Example)

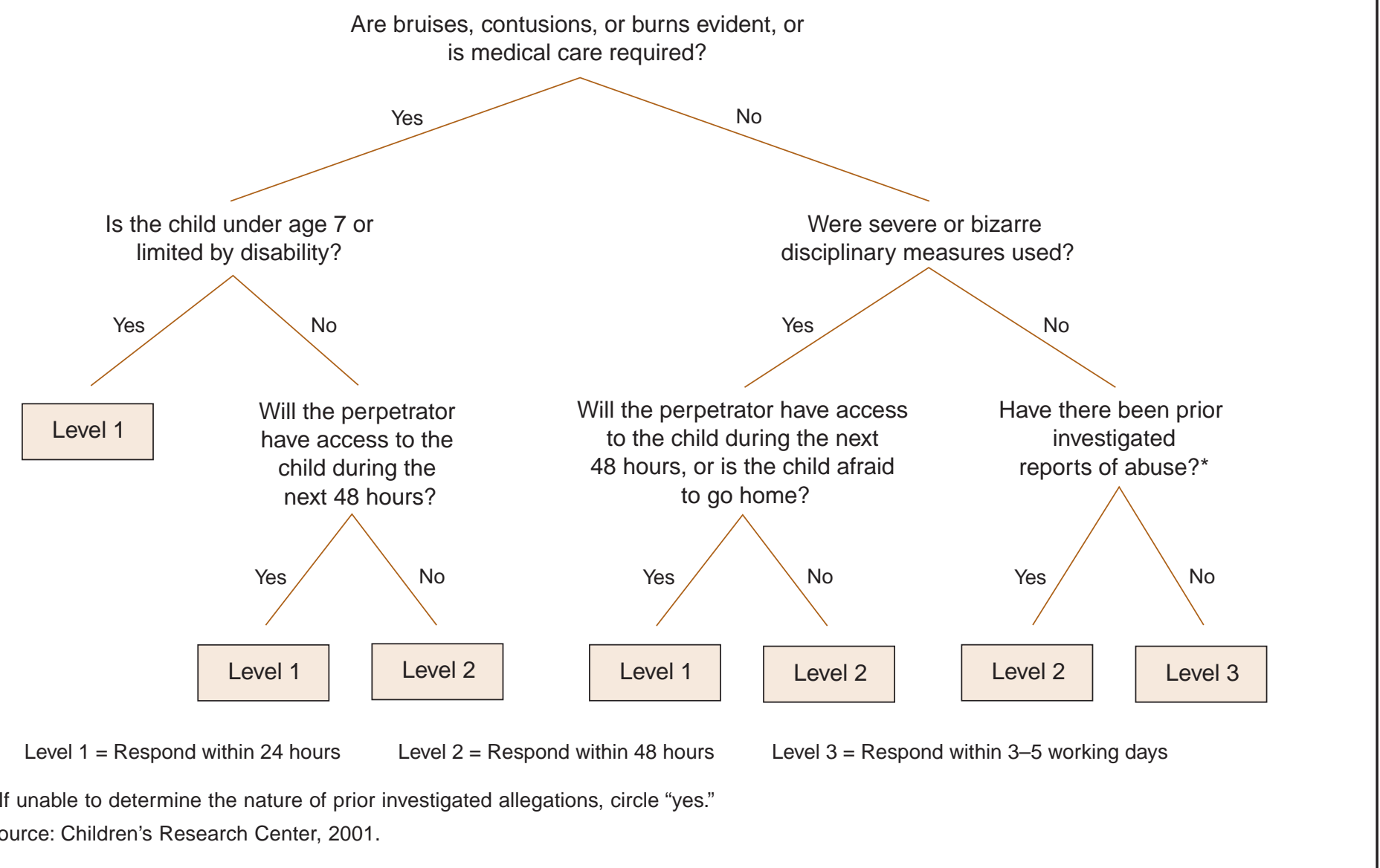

Two studies conducted to date have identified a positive relationship between the safety-related issues typically incorporated in safety assessments and subsequent harm (Illinois Department of Children and Family Services, 1997; Wagner and Caskey, 1998). For example, researchers in Illinois used a pretest-posttest design to determine whether rates of child injuries that occur within 60 days of a CPS investigation declined after the Illinois Department of Child and Family Services began using its safety assessment. Compared with the period prior to implementation, use of the safety assessment appears to have reduced subsequent child injuries (Illinois Department of Children and Family Services, 1997). ${ }^{2}$

\section{Risk Assessment}

The heart of the SDM model is its research-based risk assessment tool. Although other components of the model are based on a general consensus (often informed by available research) of what constitutes best practice, SDM risk assessment tools are based on the outcomes of actual cases. To develop a risk assessment tool, CRC and agency staff jointly identify a list of potential risk factors. These potential factors are based on

2 Due to methodological problems inherent in validating safety assessment tools, both studies provide limited validations of safety assessments. The most straightforward method of evaluating the validity of a safety assessment is to examine rates of injuries occurring within a specified period following the assessment. However, there are two major methodological barriers to such validation. The first is the low overall rate of subsequent injury in the 30 -day period immediately following the initial CPS investigative contact (a parameter often used to measure safety issues). The second is the fact that serious safety problems often result in a child's removal from the home. For these children, there is no opportunity to observe whether identified safety factors are in fact related to the (short-term) potential for additional injury. Because of these problems, both studies had to expand the timeframe used for followup analysis, and one of the studies expanded the outcome measure from child injury to any new substantiation of maltreatment. literature, experience, and previous CRC research results. $\mathrm{CRC}$ researchers then review a large sample of case records (e.g., 1,000) and code them for the presence or absence of the factors, based on what was known about each family at the time of the sampled investigation. Case records are further explored to identify families that experienced reinvolvement with the agency after the sampled investigation. The definition of "reinvolvement" generally includes subsequent CPS referrals, subsequent substantiations of maltreatment, subsequent child injuries, and subsequent CPS placements. The research process then examines the statistical relationship between case characteristics and case outcomes to identify the variables that are most closely associated with risk. The set of risk factors that most effectively divides families into three or four different risk groups constitutes the risk assessment tool. Figure 5 (page 9) presents a risk assessment scale that is used in California. 
Figure 4: Section 1: Safety Assessment (Example)

Family Case Name:

County Name:

CPS Referral Date:
County \#:

Current Date:
Family Case \#:

Office: Worker \#:

Assessment (check one): _ Initial _ Review

\section{Part A. Safety Factor Identification}

\section{Section 1: Safety Assessment}

Directions: The factors in the following list are behaviors or conditions that may be associated with a child's being in immediate danger of serious harm. Identify the presence or absence of each factor by circling either "yes" or "no." Note: The vulnerability of each child needs to be considered throughout the assessment. Children ages 0 through 6 cannot protect themselves. For older children, inability to protect themselves could result from diminished mental or physical capacity or repeated victimization.

1. Yes No Caregiver's behavior is violent or out of control.

2. Yes No Caregiver describes or acts toward child in predominantly negative terms or has extremely unrealistic expectations.

3. Yes No Caregiver caused serious physical harm to the child or has made a plausible threat to cause serious physical harm.

4. Yes No The family refuses access to the child, or there is reason to believe that the family is about to flee, and/or the child's whereabouts cannot be ascertained.

5. Yes No Caregiver has not provided or will not provide supervision necessary to protect child from potentially serious harm.

6. Yes No Caregiver is unwilling or unable to meet the child's immediate needs for food, clothing, shelter, and/or medical or mental health care.

7. Yes No Caregiver has previously maltreated a child, and the severity of the maltreatment, or the caregiver's response to the previous incident(s), suggests that child safety may be an immediate concern.

8. Yes No Child is fearful of caregiver(s), other family members, or other people living in or having access to the home.

9. Yes No The child's physical living conditions are hazardous and immediately threatening.

10. Yes No Child sexual abuse is suspected, and circumstances suggest that child safety may be an immediate concern.

11. Yes No Caregiver's drug or alcohol use seriously affects his/her ability to supervise, protect, or care for the child.

12. Yes No Other (specify)

\section{IF NO SAFETY FACTORS ARE PRESENT, GO TO SECTION 3: SAFETY DECISION}

\section{Part B. Safety Factor Description}

Directions: For all safety factors that are marked "Yes," note the applicable safety factor number and then briefly describe the specific individuals, behaviors, conditions, and/or circumstances associated with that particular safety factor. 


\section{Figure 5: California Family Risk Assessment Scale}

Family Case Name:

County Name:

Worker Name:

Neglect

N1. Current Referral Is for Neglect

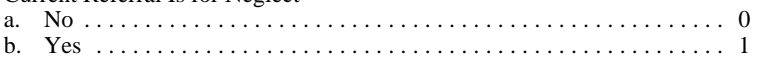

N2. Number of Prior Referrals

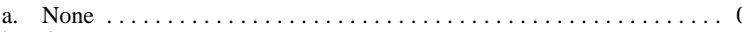

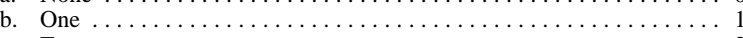

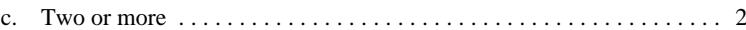

N3. Number of Children in the Home

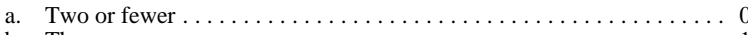

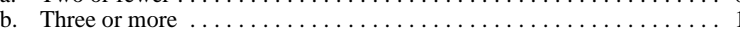

N4. Number of Adults in Home at Time of Referral

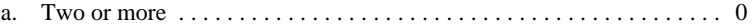

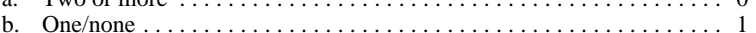

N5. Age of Primary Caregiver

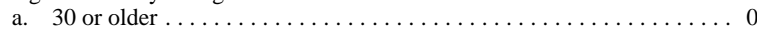

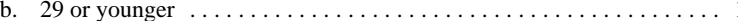

N6. Characteristics of Primary Caregiver (check and add for score)
a. Not applicable $\ldots \ldots \ldots \ldots \ldots \ldots \ldots \ldots \ldots \ldots \ldots \ldots \ldots \ldots \ldots \ldots \ldots \ldots$
b. $\quad$ Parenting skills are a major problem $\ldots \ldots \ldots \ldots \ldots \ldots \ldots$
b. Parenting skills are a major problem $\ldots \ldots \ldots \ldots \ldots \ldots \ldots$
d. Apathetic or shows feelings of hopelessness .............

N7. Primary Caregiver Involved in Harmful Relationships

a. No $\ldots \ldots \ldots \ldots \ldots \ldots \ldots \ldots \ldots \ldots \ldots \ldots \ldots \ldots \ldots \ldots \ldots \ldots \ldots \ldots \ldots \ldots \ldots \ldots \ldots \ldots$
b. Yes, but not a victim of domestic violence $\ldots \ldots \ldots \ldots \ldots \ldots$

c. Yes, as a victim of domestic violence ..........................

N8. Primary Caregiver Has a Current Substance Abuse Problem

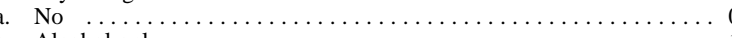

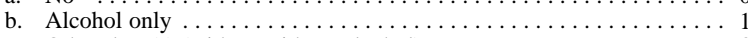
c. Other $\operatorname{drug}(\mathrm{s})$ (with or without alcohol) $\ldots \ldots \ldots \ldots \ldots \ldots \ldots \ldots$

N9. Household Is Experiencing Severe Financial Difficulty

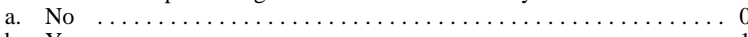

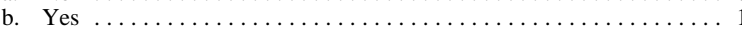

N10. Primary Caregiver's Motivation To Improve Parenting Skills

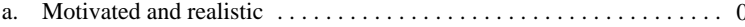

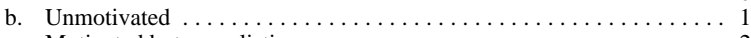

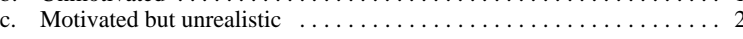

N11. Response of Caregiver(s) to Investigation and Seriousness of Complaint

a. Attitude is consistent with seriousness of allegation,

b. Attitude not consistent with seriousness of allegation (minimizes) $\ldots \ldots$

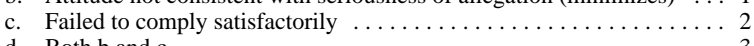

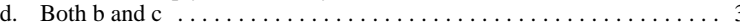

\section{TOTAL NEGLECT RISK SCORE}

INITIAL RISK LEVEL

Assign the family's risk level based on the highest score

on either scale, using the following chart:

\begin{tabular}{ccc} 
Neglect Score & Abuse Score & \multicolumn{2}{c}{ Risk Level } \\
\cline { 2 - 3 }$-0-4$ & $0-2$ & Low \\
$5-7$ & $3-5$ & - Moderate \\
$8-12$ & $6-9$ & - High \\
$13-20$ & $-10-16$ & - Intensive
\end{tabular}

FINAL RISK LEVEL Low Moderate High Intensive
Family Case \#:

Office:

county \#:

Assessment Date:

Score

Score Abuse

A1. Current Referral Is for Physical, Sexual, or

Emotional Abuse

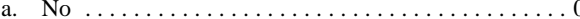

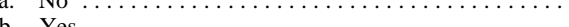

A2. Prior Abuse Referrals

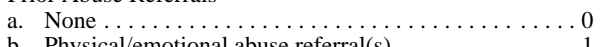

b. Physical/emotional abuse $\operatorname{referral}(\mathrm{s}) \quad \ldots \ldots \ldots \ldots \ldots 1$

c. Sexual abuse referral(s) $\ldots \ldots \ldots \ldots \ldots \ldots \ldots$

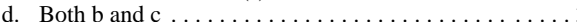

A3. Prior CPS Service History

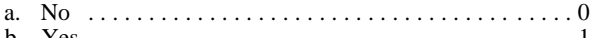

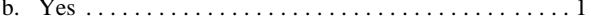

A4. Number of Children in the Home

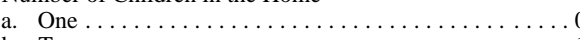

b. Two or more $\ldots \ldots \ldots \ldots \ldots \ldots \ldots \ldots \ldots \ldots$

A5. Caregiver(s) Abused as Child(ren)

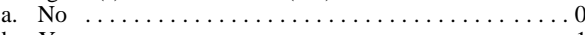

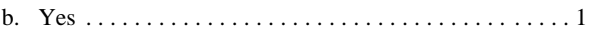

A6. Secondary Caregiver Has a Current Substance Abuse Problem

a. No, or no secondary caregiver .............. 0

b. Yes (check all that apply)

Alcohol abuse problem

Drug abuse problem

A7. Primary or Secondary Caregiver Employs Excessive and/or Inappropriate Discipline

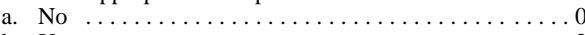

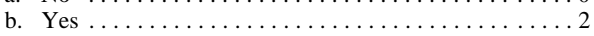

A8. History of Domestic Violence by Caregiver(s)

a. No $\ldots \ldots \ldots \ldots \ldots \ldots \ldots \ldots \ldots \ldots \ldots \ldots \ldots \ldots \ldots \ldots \ldots \ldots \ldots \ldots \ldots \ldots \ldots \ldots \ldots \ldots$
b. Yes $\ldots \ldots \ldots \ldots \ldots \ldots$

A9. Caregiver(s) Over-Controlling

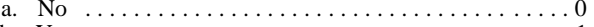

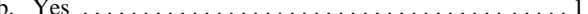

A10. Child in the Home Has Special Needs or History of Delinquency

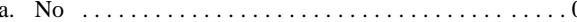

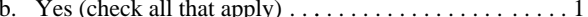

_ Diagnosed special needs

— History of delinquency

A11. Secondary Caregiver Motivated To Improve Parenting Skills

a. Yes, or no secondary caregiver in home $\ldots \ldots \ldots 0$

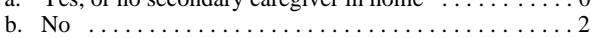

A12. Primary Caregiver's Attitude Is Consistent With the Seriousness of the Allegation

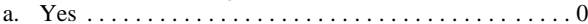

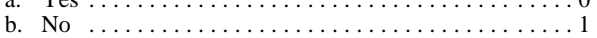

TOTAL ABUSE RISK SCORE

POLICY OVERRIDES

Policy: Override to Intensive. Check appropriate reason.

- 1. Sexual abuse case and the perpetrator is likely to have access to the child victim.

. Nonaccidental physical injury to child under 2

3. Serious nonaccidental physical injury requiring hospital or medical treatment.

- 4. Death (previous or current) of a child as a result of abuse or neglect

- 5. Positive tox screen (any drug, including alcohol) of mother or child

Discretionary Override to Risk Level

6. Override and assign new risk level

$$
\begin{gathered}
\text { Supervisor's initials } \\
\text { as approval }
\end{gathered} \frac{1 / 1}{\text { Date }}
$$

Discretionary override reason: 
The test of any risk assessment tool is how well it classifies families based on their likelihood of subsequently maltreating their children. Families identified as "high risk," for example, should be expected to have re-referral (and/or resubstantiation) rates that are significantly higher than those in families that the tool classifies as "low risk." Figure 6 illustrates this principle using the results of the California risk scale. The data show a strong relationship between risk classification and outcomes. For example, after a 2-year followup period, the California families that were assessed as low risk had a resubstantiation rate of less than 8 percent. In contrast, among families classified as very high risk, the resubstantiation rate was 44 percent or more than five times the rate found for low-risk cases.

The 11 risk assessment studies that CRC has completed to date lead to the following conclusions:

- A child's risk of subsequent abuse and his or her risk of subsequent neglect are best approached as separate issues. Although some risk factors relate to both types of maltreatment (and, indeed, some families both abuse and neglect children), there are enough differences between the family characteristics and dynamics associated with abuse and those associated with neglect to warrant the use of separate scales to address each type of maltreatment.
- Risk instruments developed in one jurisdiction appear to transfer well to other locations. For example, the risk assessment instrument developed in Michigan has been shown to effectively classify families based on risk in California, Florida, and Missouri (Baird and Wagner, 2000), and a risk tool developed in Wisconsin has proved effective with a predominantly Hispanic population in Texas (Wood, 1997). Still, when an agency adopts another jurisdiction's risk assessment instrument, it is critical that the agency routinely collect data to validate (and, if necessary, revise) the instrument within 2 years of implementation.

Prediction versus classification. The risk level assigned to a case is not a prediction that a family will or will not maltreat a child in the future. Instead, a risk level designation simply denotes a case's inclusion in a group of families with relatively high or low historical rates of subsequent maltreatment. Accurate prediction in any field is difficult; prediction of human behavior is especially complex because many factors contribute to determining how individuals will act. Classification, on the other hand, is simply a systematic arrangement of clients into groups or categories according to established criteria. In the CPS context, classification is meant to assign cases to different risk categories based on observed outcome rates. Knowing that cases with certain similar characteristics have recidivism rates of 5 percent, 25 percent, or 50 percent helps social workers (and

\section{Figure 6: Subsequent Substantiation Rates by Risk Classification: California (2-Year Followup)}

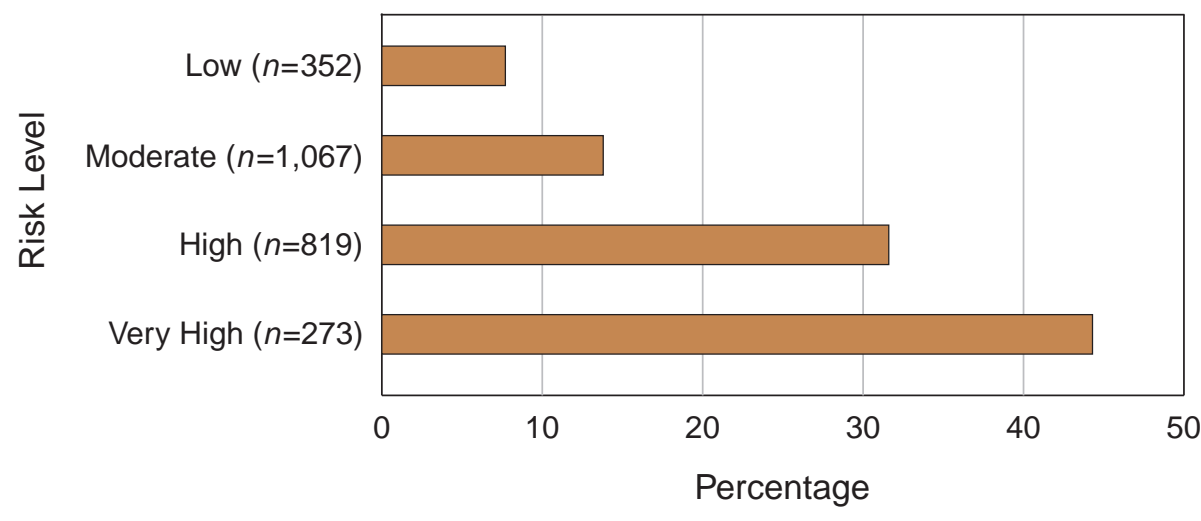

Source: Children's Research Center, 1998a.

agencies) determine appropriate levels of intervention and allocate scarce resources in an effective manner.

Decisions affected by risk assessment. Agencies typically use risk assessment results to guide decisions about whether families should have their cases opened for ongoing CPS services (e.g., moderate and high risk) or not (e.g., low risk). For cases that are opened, risk results are also typically used to determine the level of intervention required. The link between risk levels and service standards is discussed in greater detail later in this Bulletin (see page 11).

Agencies should rely primarily on safety assessment results, rather than the risk assessment, to make protective placement decisions. Even among very highrisk families, about half will not have another substantiated incident of maltreatment. A policy that required protective placement of all very high-risk children, therefore, would lead to overuse of such placements, resulting in a crushing demand on scarce resources and unduly increasing the number of children and families who must endure the emotional impact that such placement brings.

\section{Family Strengths and Needs Assessments}

For families receiving ongoing CPS services, staff must decide precisely what services to provide and what the case plan objectives are. A family strengths and needs assessment (FSNA) covers a comprehensive array of critical domains of family life that affect the care of children (e.g., substance abuse, parenting skills, domestic violence). Families are rated on each domain along a continuum from strength to severe need. Definitions for each item and rating level help reduce subjectivity in these assessments. Items are weighted so that once completed, the assessment can identify a family's three most critical needs. Case plans, by policy, are to address those critical needs. With FSNAs, case plans are less likely to omit critical needs. Conversely, FSNAs help prevent case plans from including voluminous recommendations that are overwhelming for families.

More recent applications of the FSNA reflect the trend toward strength-based practice, requiring workers to identify a family's greatest strengths. Even though 
the literature has promoted strengthbased practice for some time, the philosophy is rarely applied in the field. Including strengths in the SDM model helps make the practice more routine.

In sum, FSNA instruments do the following:

- Ensure that all CPS workers consistently consider each family's strengths and weaknesses in an objective format when assessing the family's need for services.

- Provide workers and first-line supervisors an important case planning reference that eliminates long, disorganized case narratives and reduces paperwork.

- Provide a basis for monitoring whether appropriate service referrals are made.

- Through initial needs assessments followed by periodic reassessments, permit caseworkers and supervisors to easily evaluate change in family functioning and thus monitor the impact of services on the case.

- Provide management with profiles containing aggregate information on the issues that client families face. These profiles can be used to develop resources to meet client needs.

One purpose of the FSNA is to allow caseworkers to consistently identify critical concerns facing families. Services provided to enhance child safety should not vary based on which worker has been assigned to a case. To what extent do these tools, in fact, promote consistency in the assessment process? Reliability testing has demonstrated a relatively high rate of interrater reliability for most items on SDM strengths and needs assessment instruments. Research conducted in California (Children's Research Center, 1998b) found that for caseworker assessments of whether a need existed, without regard to the severity of the need, most items had interrater reliability rates above 80 percent. For items that address some of the most critical issues facing CPS populations, such as substance abuse and mental health problems, rates of agreement were at or near 90 percent.

When the measure of agreement was based on workers' scoring of "needs" exactly the same along a four-point continuum (from "strength" to "severe need"), rates of agreement declined to some degree but remained high for key issues such as substance abuse (85 percent agreement), family relationships (70 percent), domestic violence (69 percent), and parenting skills (64 percent).

\section{Risk and Needs Reassessment}

Initial assessments of a family's risk level and service needs are followed by routine reassessments, conducted at established intervals (generally every 90 days) for as long as the case is open. Reassessment ensures that any potential changes in the family's risk level or service needs will be considered in subsequent stages of the service delivery process and that case decisions will be made accordingly. Case progress determines whether a lower or higher level of service is needed or whether the case can be closed. In most agencies, risk and needs assessment and reassessment instruments have become formal case planning documents and thus reduce the need for long case narratives and other paperwork.

Periodic reassessment also allows agencies to monitor important case outcomes on an ongoing basis. Such outcomes include new abuse or neglect incidents, changes in out-of-home placement status of children in the family, changes in a family's service utilization pattern, and changes in the severity of identified needs. In short, reassessing each family at fixed intervals provides direct service workers and their supervisors with an efficient mechanism for collecting and evaluating information necessary to effectively manage their cases.

\section{Risk-Based Service Standards}

Not all families that have been referred to CPS for child abuse or neglect require the same level of child welfare services. Yet, in terms of case assignment and resource allocation, many child welfare agencies treat all cases the same. Hence, agencies sometimes provide services to families that may not need them and at the same time fail to provide other, higher risk families with the resources needed to adequately protect children.

Risk assessment provides CPS agencies an objective framework within which to make service decisions. It also allows them to allocate service resources more efficiently. A primary mechanism for focusing resources is the use of differential service standards, under which the mandated frequency of caseworker-family contact is tied to the family's level of risk. Low-risk families do not need the same amount of agency resources (i.e., caseworker time) as high-risk families because the former are much less likely to maltreat their children again. When an agency establishes and uses differential service standards based on risk, existing service resources can reach farther and better results are possible. Figure 7 (page 12) shows how the Michigan Family Service Agency has defined and differentiated service standards by risk level. Many other agencies have implemented similar standards.

\section{SDM for Children in Out-of-Home Care}

CRC also has applied the principles of standardized assessment and structured decision making to families that have children in foster care. SDM's foster care component is designed to ensure that State and Federal policies regarding reunification of families, permanency planning for children, and termination of parental rights are translated effectively into practice. To this end, the SDM model's presumptive guidelines for children in foster care are based on children's risk of future maltreatment, the safety of the home environment, and demonstrated parental interest and involvement in the lives of their children. The SDM foster care guidelines are a "best practice" tool that will facilitate implementation of new Federal legislation while leading to more consistent and appropriate decision making. Although every agency needs to modify this component of the SDM model to include its own assessment instruments, policies, and terminology, the overall logic of the component is universally applicable.

SDM guidelines governing children in outof-home care are based on the following assumptions:

- When a family reduces risk to an acceptable level and maintains appropriate visitation with a child, the child should be returned home if the home is judged to be safe.

- When risk remains high, the home remains unsafe, or parents fail to meet their visitation responsibilities for a specified period (as set by Federal guidelines and/or agency policy), the goal for the case changes from returning the child home to developing another plan for permanency.

In SDM's foster care model, the initial risk level is established by using the researchbased risk assessment instrument. The risk reassessment will reflect a reduced 
Figure 7: Michigan Contact Standards for CPS Workers by Risk Level

\begin{tabular}{|c|c|c|c|}
\hline Case Type & $\begin{array}{l}\text { Number of Required } \\
\text { Face-to-Face } \\
\text { Contacts per Month }\end{array}$ & Contact Level & Collateral Contacts \\
\hline Low Risk & 1 & $\begin{array}{l}\text { Face-to-face with child and/or } \\
\text { parent/caretaker }\end{array}$ & 1 \\
\hline Moderate Risk & 2 & $\begin{array}{l}\text { Face-to-face with child and/or } \\
\text { parent/caretaker }\end{array}$ & 2 \\
\hline High Risk & 3 & $\begin{array}{l}\text { Face-to-face with child and/or } \\
\text { parent/caretaker }\end{array}$ & 3 \\
\hline Intensive Risk & 4 & $\begin{array}{l}\text { Face-to-face with child and/or } \\
\text { parent/caretaker }\end{array}$ & 4 \\
\hline $\begin{array}{l}\text { Purchase of Service } \\
\text { (POS) Through } \\
\text { Private Agency }\end{array}$ & $\begin{array}{l}\text { Varies, but minimum } \\
\text { once per month }\end{array}$ & $\begin{array}{l}\text { Worker contacts can be replaced on } \\
\text { one-for-one basis by POS agency worker }\end{array}$ & $\begin{array}{l}2 \text { Phone calls per month } \\
\text { with agency worker }\end{array}$ \\
\hline Families First/FTBS* & 1 & $\begin{array}{c}1 \text { contact per month with Families First } \\
\text { or FTBS worker }\end{array}$ & None required \\
\hline Pending Adjudication & None required & Contacts as needed & None required \\
\hline
\end{tabular}

* Families Together Building Solutions.

Source: Michigan Family Independence Agency, 1996.

level of risk if the family has made significant progress toward treatment goals. However, the reassessment scoring system generally precludes a family from receiving a lower risk score if there has been any new substantiation of maltreatment of any child in the household since the previous assessment.

The reunification model consists of four assessment components:

- A structured risk reassessment.

- A structured evaluation of parental compliance with visitation schedules.

- A reunification safety assessment.

- Structured guidelines for changing the permanency planning goal.

As shown in figure 8 (presented as an example), results of the structured assessments (risk, visitation compliance, and safety) are considered jointly to guide decisions regarding a child's return to the home or changes in the permanency plan. In practice, CRC staff work with each agency to develop a protocol incorporating criteria that reflect key local policies and regulations.

\section{Summary}

The heart of SDM is a series of assessment tools and associated decision-making protocols that are designed to bring greater structure, objectivity, and consistency to child welfare practices. The model is also designed to assist agencies in systematically identifying the most problematic cases-and focusing resources on those families-in an effort to reduce the incidence of subsequent maltreatment. SDM assessment tools incorporate four qualities that are essential to improved decision making in child welfare: reliability, validity, equity, and utility. Reliability reduces the extent to which decisions vary simply because different workers bring different perspectives to CPS decision making. Validity helps ensure the accuracy of the decision-making process. Equity ensures that families are treated fairly, regardless of race or ethnicity. Finally, the tools must be useful both for workers making day-to-day decisions and, through the aggregate data generated by the system, for administrators making policy, program, and budget decisions. The utility of SDM for child welfare management practices is discussed in the following section.

\section{Management Components of the SDM Model}

In addition to helping agencies improve the consistency of their decision-making process and make more efficient use of their resources, the SDM model includes two components designed specifically to facilitate the management and administration of child welfare agencies. These components-workload measurement and management information reportsbuild on and help maximize the usefulness of the model's decision-making components.

\section{Workload Measurement}

The model's workload measurement component is based on the assumption that simple caseload counts do not adequately capture the amount of time-and therefore the number of staff membersneeded to fulfill a child welfare agency's 
Figure 8: Placement/Permanency Plan Guidelines (Example)

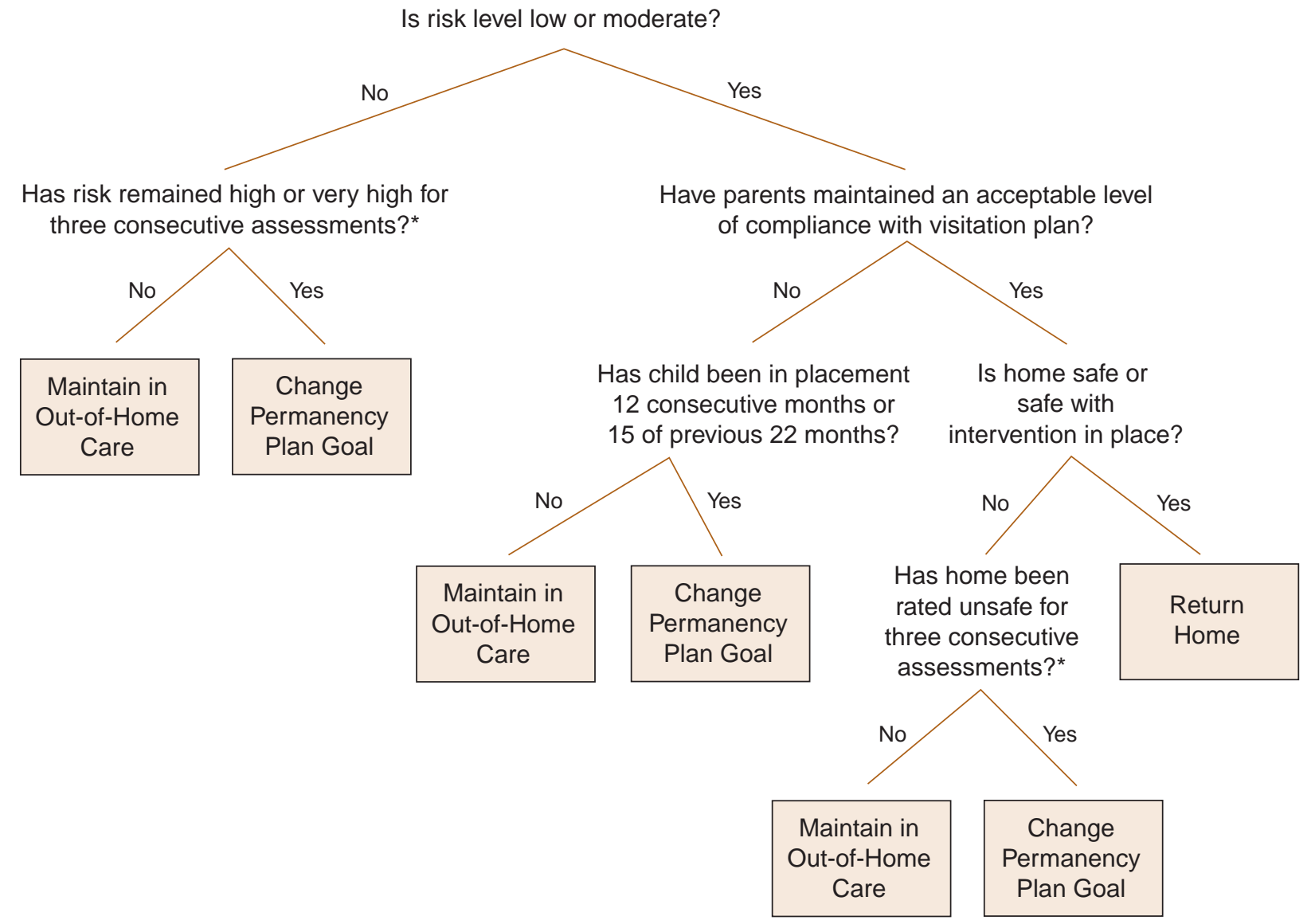

* Agency policy will determine number of assessments conducted before a change in the permanency plan is indicated.

Source: Children's Research Center, 2001.

mandates. Moreover, given the SDM model's delineation of distinct case types and differential service standards, caseload counts are an ineffective measure for determining how workload should be distributed across work units or among individual staff members. Workload measurement translates a caseload into time requirements and, ultimately, into staffing needs. To establish a workload measurement system, agencies need to conduct a simple case-based time study and determine the amount of time that staff actually need to meet service standards for various types of cases. This information is used to calculate the agency's total workload "demand," which can then be compared with the agency's current "supply" of available staff. Knowing both the monthly time requirement for each type of case and the total workload demand allows an agency to:
- Provide a rational, empirical basis for budget and staffing requests to external funding sources.

- Develop an internal system for equalizing workload across work units or among staff members.

- Estimate the impact of new service responsibilities or budget restrictions on the agency's delivery of services.

Because a workload-based budget allows an agency to specify its case-related service standards and identify the number of staff members required to serve cases according to those standards, such a budget becomes, in essence, a service contract with funding sources. If, for example, a funding body agrees that highrisk cases should be seen by staff at least four times per month, it becomes the funding body's responsibility to provide a sufficient number of staff to allow the agency to meet that level of service. With a workload-based budget, funding bodies will know exactly what level of service will be provided based on the level of staff resources allocated. The effect of budget reductions on client service will be readily apparent, as will the effect of increases in resources. Workload measurement translates caseload into time requirements and, ultimately, staffing needs.

\section{Quality Assurance and Evaluation Using SDM Management Information}

Since the implementation of the Federal standards that accompany the Adoption and Safe Families Act of 1997, the emphasis on accountability in child welfare has reached new heights. Agencies now know that their decisions will be monitored for 
compliance with Federal mandates and State policy. An important feature of the SDM model, therefore, is that it provides information that allows agency management to routinely monitor compliance with standards, assess the impact of policy, identify service needs, and identify programs and intervention strategies that provide the best results for various types of cases. A basic premise underlying SDM is that the information needed to make good decisions at the individual case level (e.g., structured assessments of risk and service needs) is the same information needed in aggregate form by agency supervisors, analysts, and administrators. Figures 9 and 10 illustrate how agency managers can use aggregate information drawn from SDM records. Aggregate risk information can document changes in the nature of the client population. The data in figure 9, for example, reveal significant increases over a 5-year period in the proportion of substantiated cases identified as "high" and "very high" risk, clearly documenting changes in workload and indicating that new challenges face the agency. Figure 10 shows how managers can use needs and service referral data to monitor the extent to which clients are receiving services for identified problems and the effectiveness of those services in terms of reducing subsequent substantiated incidents of maltreatment.

\section{Figure 9: Changes in Initial Risk Levels of Sub- stantiated Cases, 1993-98 (Example)}

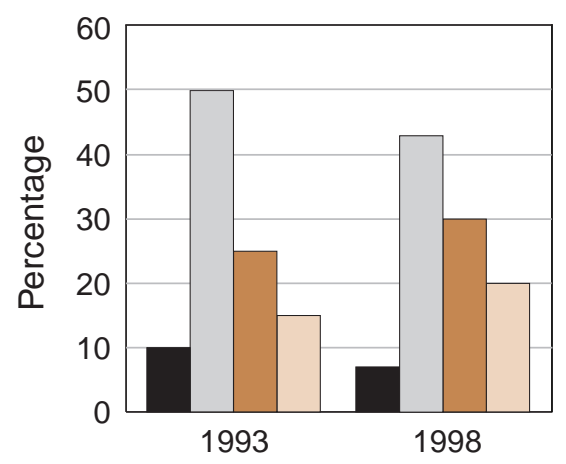

Risk Levels

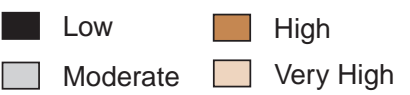

Source: Children's Research Center, 1999.

\section{Figure 10: CPS Families With Serious or Chronic Substance Abuse}

Problems: Service Needs, Referrals, and Outcomes

Families Assessed

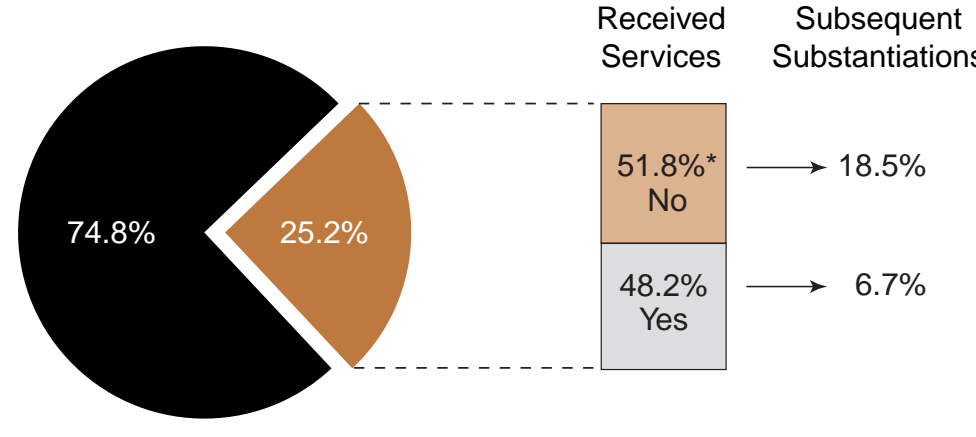

Families without serious or chronic substance abuse problems

Families with serious or chronic substance abuse problems

* Of these, services were unavailable for $1.7 \%, 12.7 \%$ refused services, and $37.4 \%$ received no referral.

Source: Baird et al., 1995.

\section{Evaluations of the SDM Model}

Few case management systems used in child welfare have been subjected to as much empirical scrutiny as the SDM model. This section summarizes some of the most salient evaluation research conducted in relation to SDM during the 12 years in which the model has been used in child welfare. The SDM system has been examined on two primary levels:

- The extent to which SDM instruments add reliability, validity, and equity to decision making (i.e., whether they enhance consistency, accurately measure what they purport to measure, and treat races fairly).

- The extent to which SDM is effective in reducing the subsequent maltreatment of children, as measured by outcome evaluations.

The next section presents the results of studies that have examined the reliability and validity of SDM risk assessment tools. This section is followed by a summary of impact evaluations conducted to date in Michigan.

\section{Evaluation of Research- Based Risk Assessment}

CPS agencies have traditionally relied on clinical judgment to establish the risk levels of families served by the system. However, recent research (Rossi, Schuerman, and Budde, 1996) has demonstrated that clinical decisions regarding the safety of children vary significantly from worker to worker, even among those considered to be child welfare experts. Moreover, although consensus-based risk assessment tools were developed to enhance consistency among caseworkers and improve decision making, recent studies indicate that the reliability and validity of these instruments are well below accepted standards (Baird et al., 1999; Baird and Wagner, 2000; Falco, in press).

Comparative reliability and validity of different risk assessment models. A study that $\mathrm{CRC}$ recently completed for the U.S. Department of Health and Human Services' Office of Child Abuse and Neglect (OCAN) compared the reliability and validity of three risk assessment tools. Two were consensus-based tools (the Washington State model and the Fresno, CA, risk assessment, 3 which is a derivative of the Illinois CANTS system). The third was a research-based instrument (the Michigan version of SDM risk assessment).

\footnotetext{
${ }^{3}$ The California risk assessment tool in this study was a consensus-based model that was used prior to the implementation of SDM.
} 
To measure the reliability of the models, 80 randomly selected cases were assessed by 4 case readers using the Washington model, 4 using the Fresno model, and 4 others using the Michigan tool. Two measures of reliability were examined: the percentage of cases in which raters reached the same conclusion about risk level and Cohen's Kappa, a statistical measure of reliability. ${ }^{4}$ The results for the research-based Michigan risk tool showed that at least three of the four raters agreed on the risk level for 85 percent of the cases (Baird et al., 1999) (see figure 11). However, this level of agreement was obtained for only 45 percent of the cases with the California scale and 51 percent of the cases with the Washington risk tool. ${ }^{5}$ According to Cohen's Kappa, which was computed for each set of raters, the SDM system (Michigan) was again deemed far more reliable than the two consensusbased systems (see figure 12).

Because risk assessment tools attempt to classify families according to the likelihood of future maltreatment, the validity of these tools can be demonstrated by showing a significant increase in subsequent maltreatment for every increase in risk level. According to this criterion, the OCAN study found superior validity in the research-based tool. In a sample of more than 1,400 cases from California, Florida, Michigan, and Missouri, the SDM researchbased risk assessment tool categorized families into groups with significantly different risk levels. The families classified as higher risk had many more subsequent substantiations of maltreatment than the families classified as lower risk. The consensus-based tools, on the other hand, sorted families into risk levels that had little correlation with actual outcomes

\footnotetext{
4 Cohen's Kappa is essentially a measure of the extent to which raters agree in their assessment of cases beyond that which would occur by chance alone. As Baird and Wagner (2000:738-739) point out, "There is no definitive Kappa threshold that designates an acceptable level of reliability, but Kappas below .3 generally indicate a very weak level of reliability. Although researchers vary on what is considered adequate, a Kappa above .5 to .6 is generally deemed acceptable." For a full description of Cohen's Kappa, see Rossi, Schuerman, and Budde, 1996:16-17.

5 When the criterion was 100-percent agreement among the raters (i.e., all four agreed on the risk level), the Michigan instrument also significantly outperformed the two consensus-based instruments. The raters using the Michigan scale had perfect agreement for 58 percent of the cases; however, the raters using the California scale all agreed on only 29 percent of the cases and those using the Washington scale all agreed on 39 percent of the cases.
}

\section{Figure 11: OCAN Risk Assessment Reliability Study: Percentage of Cases With at Least 75-Percent Rater Agreement for Overall Risk}

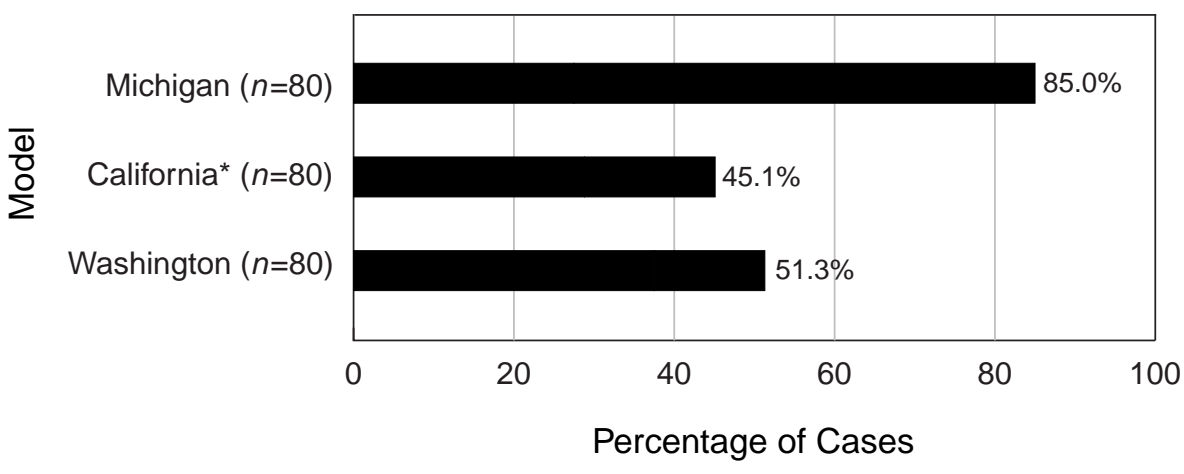

* The California risk assessment involved in this study was a consensus-based tool that predated California's implementation of SDM and research-based risk assessment.

Source: Baird et al., 1999.
(Baird et al., 1999). These findings are shown in table 1 (page 16). For each risk model, the table shows the percentage of cases at each risk level that had subsequent investigations and substantiations during an 18-month followup. The data show that for both outcome measures there was little difference between families classified as moderate risk and families classified as high risk by the California model. Further, there was little difference in subsequent substantiations for the families classified at each risk level on the Washington model. In contrast, there were significant differences in outcomes by risk classification when the Michigan model was used to assess the families.

Research-based risk assessment and equity. Disproportionate numbers of minority children, particularly African Americans, are placed in foster care, and minority children spend more time in placement than their Caucasian counterparts (Hill, 2001). This disproportionality was the case long before SDM was introduced and remains a prevalent pattern, raising the issue of equity in CPS decision making. Because empirically based risk assessment tools use information related

\section{Figure 12: OCAN Risk Assessment Reliability Study: Cohen's Kappa Among Raters for Overall Risk}

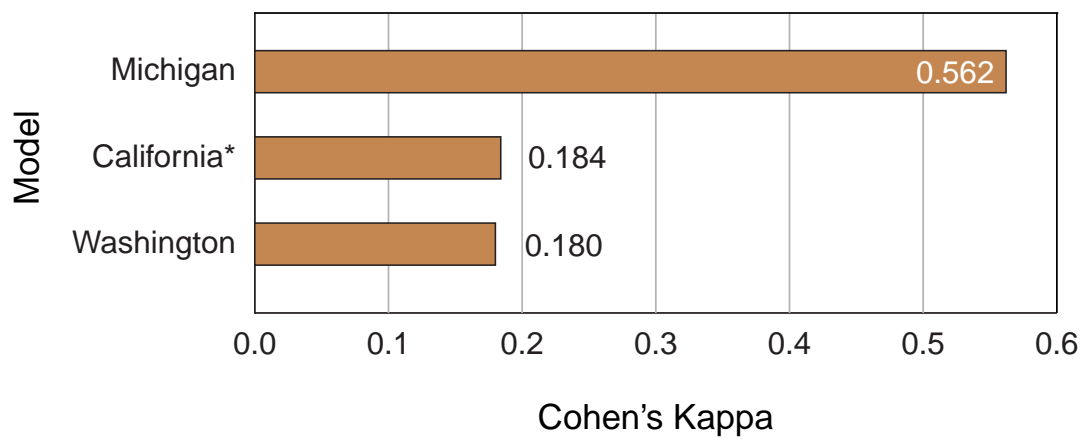

* The California risk assessment involved in this study was a consensus-based tool that predated California's implementation of SDM and research-based risk assessment.

Source: Baird et al., 1999. 


\section{Table 1: OCAN Risk Assessment Validation: Percentage of Cases With Subsequent Investigations and Substantiations, by Risk Level (18-Month Followup)}

\begin{tabular}{|c|c|c|c|c|c|c|}
\hline \multirow[b]{2}{*}{ Risk Level } & \multicolumn{2}{|c|}{ California Model $^{*}(n=876)$} & \multicolumn{2}{|c|}{ Michigan Model $(n=929)$} & \multicolumn{2}{|c|}{ Washington Model ( $n=908)$} \\
\hline & $\begin{array}{c}\text { Subsequent } \\
\text { Investigations }\end{array}$ & $\begin{array}{c}\text { Subsequent } \\
\text { Substantiations }\end{array}$ & $\begin{array}{c}\text { Subsequent } \\
\text { Investigations }\end{array}$ & $\begin{array}{c}\text { Subsequent } \\
\text { Substantiations }\end{array}$ & $\begin{array}{c}\text { Subsequent } \\
\text { Investigations }\end{array}$ & $\begin{array}{c}\text { Subsequent } \\
\text { Substantiations }\end{array}$ \\
\hline Low & $28 \%$ & $15 \%$ & $16 \%$ & $7 \%$ & $25 \%$ & $16 \%$ \\
\hline Moderate & 38 & 18 & 32 & 15 & 35 & 16 \\
\hline High & 38 & 18 & 46 & 28 & 39 & 21 \\
\hline
\end{tabular}

* The California risk assessment involved in this study was a consensus-based tool that predated California's implementation of SDM and researchbased risk assessment.

Source: Baird and Wagner, 2000.

to poverty and other social conditions, some practitioners have questioned whether the instruments contribute to racial bias. Under the SDM system, however, foster care placement is guided by safety assessment, not risk. Risk level guides case opening and intensity of services decisions. Disproportionate representation of minority youth in foster care, therefore, should not be attributed to the use of research-based risk assessment tools.

Nevertheless, it is important to measure how SDM risk assessments perform across racial and ethnic groups. Because equity is a key principle of SDM development efforts, every SDM risk tool validated to date has been subjected to an examination of its validity within racial and ethnic populations. These tests have shown that the use of SDM instruments results in virtually equal assignment of all races and ethnicities to each risk level. Table 2 presents data from Michigan as an example of the level of equity SDM has attained. These data on more than 6,500 white and 5,000 African American families show that there is no disproportionate representation at any risk level (Baird, Ereth, and Wagner, 1999). The California Department of Social Services also conducted an independent, detailed analysis of the individual items incorporated in that State's new researchbased tool and an overall assessment of the tool's equity. The analysis found no bias in any item or in the instrument as a whole (Johnson, 1999).

Equally important findings relevant to the issue of equity have come from Baird and his colleagues. They have found that the rate of subsequent maltreatment observed within racial and ethnic groups increases with each incremental rise in risk level and that maltreatment rates within each risk category are similar among all groups (Baird, Ereth, and Wagner, 1999).

\section{Evaluation of the Michigan SDM System}

Between 1989 and 1992, CRC and Michigan child welfare staff worked together to design an SDM system for CPS cases (Baird et al., 1995). When initially implemented, the system consisted of risk and needs assessment instruments, case planning and reassessment tools, and differentiated service standards. System implementation began in 13 pilot counties in 1992.

Michigan's phased implementation schedule for the system presented an opportunity to formally evaluate the impact of SDM by comparing outcomes in the 13 pilot counties with those in a matched sample of 11 counties still operating under the traditional system. The evaluation sample included all cases with substantiated reports of abuse or neglect between September 1992 and October 1993. The SDM and comparison study samples each consisted of approximately 900 families. Outcome measures included new referrals, investigations, and substantiations during a 12-month followup period.
The evaluation revealed several important differences in decision making and case processing in the SDM and comparison counties. These findings are summarized in the sections that follow.

Case closing decisions. The SDM counties were significantly more likely than nonSDM counties to close low- and moderaterisk cases following substantiation, and the non-SDM counties were more likely than SDM counties to close high- and intensive-risk cases. Moreover, cases that were closed without services in the SDM counties had significantly lower re-referral rates than those closed without services in the comparison group. This finding indicates that the use of risk assessment led to improved decisions in the SDM counties regarding which cases could be safely closed at the completion of the investigation.

Program participation. Service program participation by families was significantly higher in the SDM counties than in the comparison counties-particularly among high- and intensive-risk families. For example, high-risk families in SDM counties were more likely than those in non-SDM counties to receive parenting
Table 2: Distribution of Families by Race and Risk Level: Michigan Risk Assessment

\begin{tabular}{lcc} 
Risk Level & $\begin{array}{c}\text { White } \\
(\boldsymbol{n}=\mathbf{6 , 6 5 1 )}\end{array}$ & $\begin{array}{c}\text { African American } \\
(\boldsymbol{n}=\mathbf{5 , 2 9 6 )}\end{array}$ \\
\hline Low & $10.5 \%$ & $11.3 \%$ \\
Moderate & 30.7 & 30.0 \\
High & 45.1 & 46.0 \\
Very high & 13.7 & 12.7
\end{tabular}

Source: Baird, Ereth, and Wagner, 1999. 


\section{Figure 13: Michigan SDM Evaluation Results: High-Risk CPS Families' Receipt of Services}

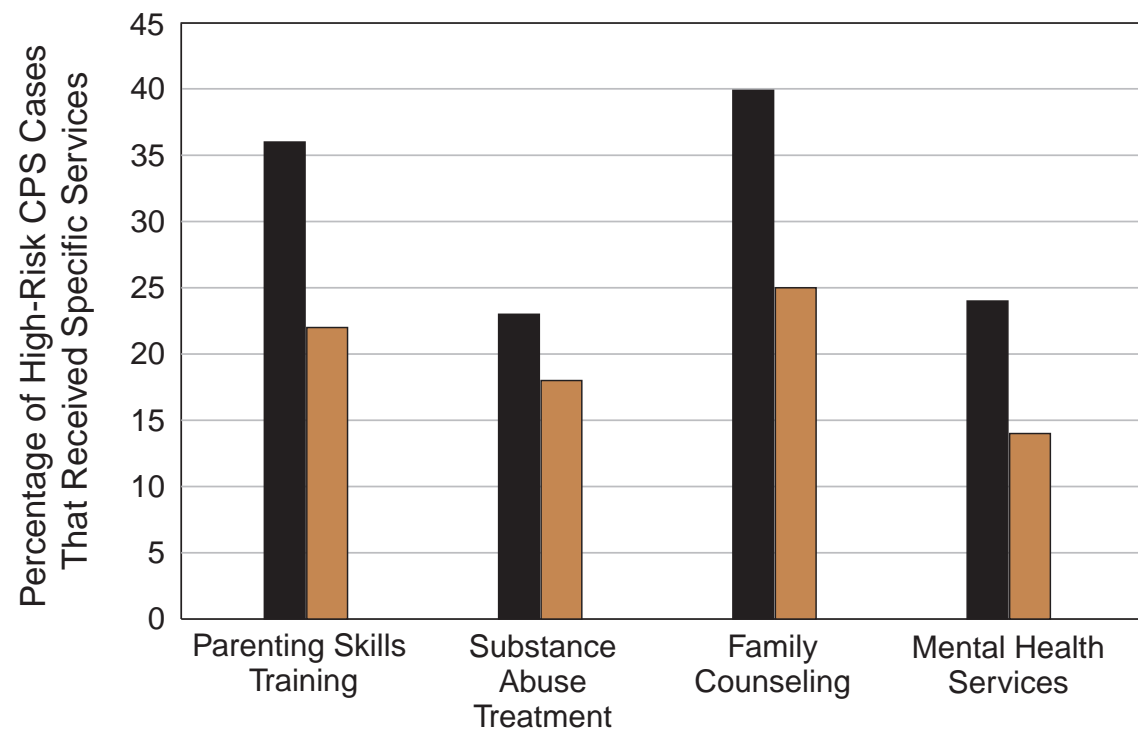

High-risk CPS families in SDM counties ( $n=360$ )

High-risk CPS families in comparison counties ( $n=367)$

Source: Baird et al., 1995.

Figure 14: Michigan SDM Evaluation Results: CPS Case Results

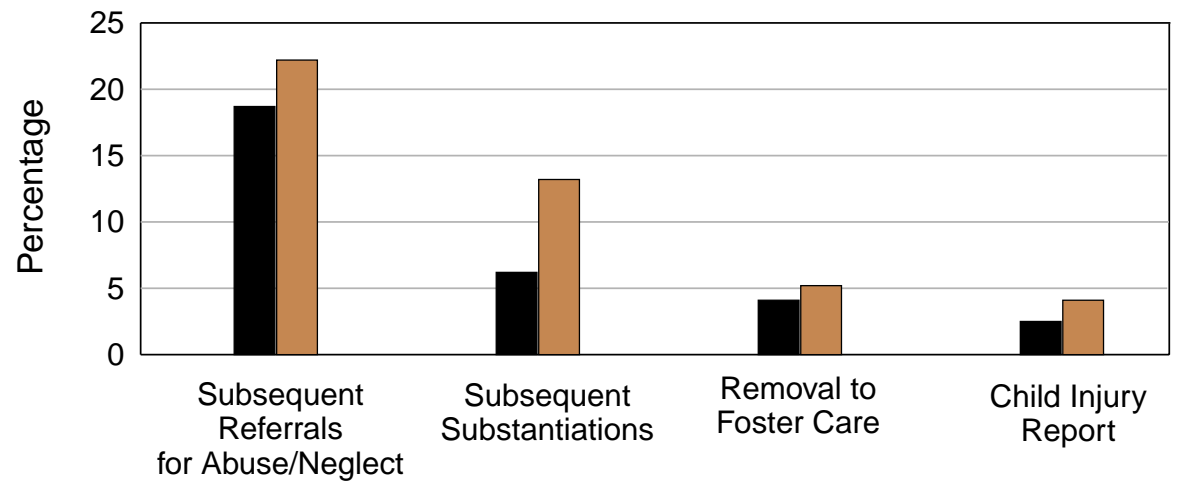

Outcomes for CPS Cases

(12-month followup)

CPS families in SDM counties $(n=518)$

CPS families in comparison counties $(n=536)$

Source: Baird et al., 1995.

skills training, substance abuse treatment, family counseling, and mental health services (see figure 13). This outcome is likely a result of the clear identification (via the risk assessment) of these families as being more likely to reabuse or reneglect their children and the more consistent identification of existing problems (via the SDM strengths and needs assessment).
Outcomes. The evaluation also examined whether implementation of the SDM system resulted in a better overall system of child protection-and, in particular, lower rates of subsequent maltreatment. Families in the SDM and comparison counties were followed for 12 months to determine whether use of the SDM system resulted in lower rates of re-referral or resubstantiation. Figure 14 compares results for CPS cases in SDM counties with those in nonSDM counties. For every outcome measure, families in the SDM counties had better results than families in the comparison counties. The greatest difference was in rates of subsequent maltreatment substantiations: that rate was 50 percent lower in SDM counties than in non-SDM counties (6.2 percent versus 13.2 percent).

An analysis of outcomes by risk group also showed positive results for the Michigan SDM system. For example, highrisk CPS cases handled in the SDM counties had fewer subsequent referrals for maltreatment and fewer subsequent child injuries than high-risk cases in the nonSDM counties. They also had lower rates of subsequent placement in foster care and were only half as likely to have a subsequent maltreatment substantiation.

Summary. The results of this carefully controlled evaluation show not only that SDM resulted in important changes in decision making and service provision for child welfare cases but, as anticipated, that it ultimately had a positive impact on the protection of Michigan's children. Although the rigor of the Michigan study has not been duplicated in other agencies, data from Wisconsin counties seem to support the Michigan findings. In Wisconsin, highand very high-risk cases that were opened for services had much lower rates of subsequent reports of maltreatment than cases at similar levels of risk that did not receive child protection services. ${ }^{6}$ As table 3 (page 18) illustrates, high levels of intervention in these cases lowered the rate of subsequent reports dramatically. At the same time, services had negligible effects on low- and moderate-risk families

6 In these Wisconsin counties, all investigated cases are assessed on risk. However, a large proportion of cases are not opened for services because the current allegation has not been substantiated. Hence, this analysis compares the outcomes of substantiated cases at each risk level with those of unsubstantiated cases at each risk level. The comparison is appropriate because the risk assessment instrument has been validated on both the substantiated and unsubstantiated populations. 
(Wagner and Bell, 1998). Thus, data from both Michigan and Wisconsin indicate that accurate identification of families with the greatest potential for subsequent maltreatment, together with appropriate allocation of resources, can play a significant role in protecting children from harm.

\section{Conclusion}

Although a large proportion of children involved in the child welfare system subsequently become involved in the juvenile justice system, statistics alone do not adequately tell the story of these children. To fully understand the toll exacted by child abuse and neglect, policymakers must read the files of incarcerated youth. Many of these youth come from abusive homes and often have moved in and out of foster care for years before ending up in the juvenile correctional system. Few have ever known a truly stable home environment.

Any program that effectively reduces abuse and neglect can serve as a prevention strategy for juvenile delinquency. Given the firmly established relationship between abuse/neglect and subsequent delinquency and criminality, it seems imperative that policymakers embrace emerging technologies that significantly improve decision making and help communities devote resources to children and families most at risk. It is clearly time to resolve age-old conflicts between clinical judgment and structured decision making. In particular, the use of empirically based risk assessment is not a question of replacing professional judgment with statistical inference; it is simply a matter of using the best information available to protect children from harm.

As demonstrated by the OCAN and Michigan evaluation research, structured decision making represents a practical and efficient way to improve the Nation's child welfare systems. By reducing the extent of maltreatment experienced by children, the SDM model can make a significant contribution to breaking the link between abuse and delinquency.

\section{References}

Alfaro, J.D. 1981. Report on the relationship between child abuse and neglect and later socially deviant behavior. In Exploring the Relationship Between Child Abuse and Delinquency, edited by R.J. Hunter and Y.E. Walker. Montclair, NJ: Allenheld, Osmun.

\section{Table 3: Percentage of 1995 Investigations Re-Referred During 2-Year Followup, by Case Opening Status and Risk Level: Wisconsin}

\begin{tabular}{lcc} 
& \multicolumn{2}{c}{ Subsequent Referrals } \\
\cline { 2 - 3 } $\begin{array}{l}\text { Risk Level at 1995 } \\
\text { Investigation }\end{array}$ & $\begin{array}{c}\text { Cases Closed } \\
\text { After 1995 } \\
\text { Investigation }(\boldsymbol{n = 1 , 0 1 4})\end{array}$ & $\begin{array}{c}\text { Cases Opened for } \\
\text { Services After 1995 } \\
\text { Investigation }(\boldsymbol{n}=\mathbf{2 1 6})\end{array}$ \\
\hline Low/moderate & $14.1 \%$ & $14.6 \%$ \\
High & 27.7 & 15.2 \\
Very high & 44.8 & 23.6
\end{tabular}

Source: Wagner and Bell, 1998.

Baird, S.C., Ereth, J., and Wagner, D. 1999. Research-Based Risk Assessment: Adding Equity to CPS Decision Making. Madison, WI: National Council on Crime and Delinquency, Children's Research Center.

Baird, S.C., and Wagner, D. 2000. The relative validity of actuarial and consensusbased risk assessment systems. Children and Youth Services Review 22(11/12): 839-871.

Baird, S.C., Wagner, D., Caskey, R., and Neuenfeldt, D. 1995. Michigan Department of Social Services Structured Decision Making System: An Evaluation of Its Impact on Child Protection Services. Madison, WI: National Council on Crime and Delinquency, Children's Research Center.

Baird, S.C., Wagner, D., Healy, T., and Johnson, K. 1999. Risk assessment in child protective services: Consensus and actuarial model reliability. Child Welfare 78(6):723-748.

Baird, S.C., Wagner, D., and Neuenfeldt, D. 1992. Protecting children: The Michigan model. Focus (March):1-7.

Bolton, F.G., Reich, J.W., and Gutierres, S.E. 1977. Delinquency patterns in maltreated children and siblings. Victimology 2:349-357.

Catalano, R.F., and Hawkins, J.D. 1995. Risk-Focused Prevention Using the Social Development Strategy. Seattle, WA: Developmental Research and Programs, Inc.

Children's Research Center. 1998a. California Preliminary Risk Assessment. Madison, WI: National Council on Crime and Delinquency, Children's Research Center.

Children's Research Center. 1998b. California Structured Decision Making System, Field Test Report. Madison, WI: National Council on Crime and Delinquency, Children's Research Center.
Children's Research Center. 1999. A New Approach to Child Protective Services: Structured Decision Making. Madison, WI: National Council on Crime and Delinquency, Children's Research Center.

Children's Research Center. 2000. Combined California Counties: Structured Decision Making Case Management Reports, January-June, 2000. Madison, WI: National Council on Crime and Delinquency, Children's Research Center.

Children's Research Center. 2001. Structured Decision Making in CPS: Generic Policy and Procedures Manual. Madison, WI: National Council on Crime and Delinquency, Children's Research Center.

Dawes, R.M., Faust, D., and Meehl, P. 1989. Clinical versus actuarial judgement. Science 243:1668-1674.

Dembo, R., Williams, L., Wothke, W., Schmeidler, J., and Brown, C. 1992. The role of family factors, physical abuse and sexual victimization experiences in high risk youths' alcohol and other drug use and delinquency: A longitudinal model. Violence and Victims 7(3):245-246.

English, D.J. 1997. Current knowledge about CPS decision making. In Decision Making in Children's Protective Services: Advancing the State of the Art, edited by T.D. Morton and W. Holder. Atlanta, GA: National Resource Center on Child Maltreatment.

Falco, G. In press. Clinical vs. Actuarial Risk Assessment: Results From New York State. Albany, NY: Office of Program Evaluation for the New York State Department of Social Services.

Gorey, K.M., and Leslie, D.R. 1997. The prevalence of child sexual abuse: Integrative review adjustment for potential response and measurement biases. Child Abuse and Neglect 21:391-398. 
Harlow, C.W. 1999. Prior abuse reported by inmates and probationers. In Bureau of Justice Statistics Selected Findings (April). Washington, DC: U.S. Department of Justice, Office of Justice Programs, Bureau of Justice Statistics.

Hill, R.B. 2001. The Role of Race in Foster Care Placements: An Outline Summary. Rockville, MD: Westat, Inc.

Howell, J.C., ed. 1995. Guide for Implementing the Comprehensive Strategy for Serious, Violent, and Chronic Juvenile Offenders. Washington, DC: U.S. Department of Justice, Office of Justice Programs, Office of Juvenile Justice and Delinquency Prevention.

Illinois Department of Children and Family Services. 1997. Illinois Child Endangerment Risk Assessment Protocol: A Report to the General Assembly Concerning the Implementation and Validation of the Protocol. Springfield, IL: Illinois Department of Children and Family Services.

Johnson, W. 1999. Race and the California family risk assessment. Paper presented at the 13th Annual CPS Risk Assessment Roundtable, San Francisco, CA.

Johnson, W., and L'Esperance, J. 1984. Predicting the recurrence of child abuse. Social Work Research and Abstracts 20(2):21-26.

Kelley, B.T., Thornberry, T.P., and Smith, C.A. 1997. In the Wake of Childhood Maltreatment. Bulletin. Washington, DC: U.S. Department of Justice, Office of Justice Programs, Office of Juvenile Justice and Delinquency Prevention.

Maxfield, M.G., and Widom, C.S. 1995. Childhood victimization and patterns of offending through the life cycle: Early onset and continuation. Paper presented at the American Society of Criminology, Boston, MA.

Michigan Family Independence Agency. 1996. CPS Policy and Procedures Manual. Lansing, MI: Family Independence Agency.

National Council on Crime and Delinquency. 1995a. Assessing the Risk of Juvenile Offenders in Nebraska. Madison, WI: National Council on Crime and Delinquency.

National Council on Crime and Delinquency. 1995b. Revalidation of the Michigan Juvenile Risk Assessment. Madison, WI: National Council on Crime and Delinquency.
National Council on Crime and Delinquency. 1995c. Rhode Island Juvenile Risk Assessment Findings. Madison, WI: National Council on Crime and Delinquency.

National Council on Crime and Delinquency. 1997. Wisconsin Juvenile Offender Classification Study: County Risk Assessment Revalidation Report. Madison, WI: National Council on Crime and Delinquency.

National Council on Crime and Delinquency. 1999. Development of an Empirically Based Risk Assessment Instrument for the Virginia Department of Juvenile Justice: Final Report. Madison, WI: National Council on Crime and Delinquency.

Pawaserat, J. 1991. Identifying Milwaukee Youth in Critical Need of Intervention: Lessons From the Past, Measures for the Future. Milwaukee, WI: University of Wisconsin Employment and Training Institute, pp. 1-12.

Rossi, P., Schuerman, J., and Budde, S. 1996. Understanding Child Maltreatment Decisions and Those Who Make Them. Chicago, IL: Chapin Hall Center for Children, University of Chicago.

Silverman, A.B., Reinherz, H., and Giaconia, R. 1996. Long-term sequelae of child and adolescent abuse: A longitudinal community study. Child Abuse and Neglect 20(8):709-723.

Snyder, H., and Sickmund, M. 1999. Juvenile Offenders and Victims: 1999 National Report. Report. Washington, DC: U.S. Department of Justice, Office of Justice Programs, Office of Juvenile Justice and Delinquency Prevention.

U.S. Department of Health and Human Services, Administration on Children, Youth and Families. 1999. Child Maltreatment 1997: Reports From the States to the National Child Abuse and Neglect Data System. Washington, DC: U.S. Government Printing Office.

Wagner, D., and Bell, P. 1998. The Use of Risk Assessment To Evaluate the Impact of Intensive Protective Service Intervention in a Practice Setting. Madison, WI: National Council on Crime and Delinquency, Children's Research Center.

Wagner, D., and Caskey, R. 1998. Safety Assessment Validation Report for the Michigan Family Independence Agency. Madison, WI: National Council on Crime and Delinquency.
Widom, C.S. 1992. The Cycle of Violence. Research in Brief. Washington, DC: U.S. Department of Justice, Office of Justice Programs, National Institute of Justice.

Widom, C.S. 1995. Victims of Childhood Sexual Abuse-Later Criminal Consequences. Research in Brief. Washington, DC: U.S. Department of Justice, Office of Justice Programs, National Institute of Justice.

Wiebush, R., McNulty, B., and Le, T. 2000. Implementation of the Intensive Community-Based Aftercare Program. Bulletin. Washington, DC: U.S. Department of Justice, Office of Justice Programs, Office of Juvenile Justice and Delinquency Prevention.

Wood, J.M. 1997. Risk predictors for reabuse or re-neglect in a predominantly Hispanic population. Child Abuse and Neglect 21(4):379-389.

Points of view or opinions expressed in this document are those of the authors and do not necessarily represent the official position or policies of OJJDP or the U.S. Department of Justice.

The Office of Juvenile Justice and Delinquency Prevention is a component of the Office of Justice Programs, which also includes the Bureau of Justice Assistance, the Bureau of Justice Statistics, the National Institute of Justice, and the Office for Victims of Crime.

\section{Acknowledgments}

Richard Wiebush and Raelene Freitag are Senior Researchers with the Children's Research Center, National Council on Crime and Delinquency. Christopher Baird is Senior VicePresident of the National Council on Crime and Delinquency. 


\section{U.S. Department of Justice}

Office of Justice Programs

Office of Juvenile Justice and Delinquency Prevention
PRESORTED STANDARD POSTAGE \& FEES PAID DOJ/OJJDP PERMIT NO. G-91

Washington, DC 20531

Official Business

Penalty for Private Use $\$ 300$ 